\title{
FORMULATING A CAPABILITY APPROACH BASED MODEL TO SUSTAIN RURAL SUB-SAHARAN AFRICAN INHABITANT'S SELF-RELIANCE TOWARDS THEIR BUILT ENVIRONMENT
}

\author{
M. SMITS \\ Faculty of Architecture, Delft University of Technology, The Netherlands ${ }^{1}$.
}

\begin{abstract}
Changing climate conditions and depleting resources are becoming more important on the global agenda, the paradigm shifting to understand which means (resources) are necessary to generate future well-being. Unfortunately, the formal built environment remains the most polluting global industry and due to its conservative character seems difficult to change. Most undertaken efforts focus on improving characteristics of material, construction and processes in technology seeking the ability to solve all contemporary environmental problems. This article argues that in the informal rural African built environment examples of other attitudes towards the same goals can be found, providing many sustainable solutions that have a circular process and are based on local renewable materials. Rural communities perceived as a multitude of communities of practices, with a collective (sustainable) intelligence towards their built environment can provide a circular, sustainable, self-reliant and resilient model for the built environment. This article argues that in order to articulate sustainable 'local' solutions, the inhabitant's self-reliance is of vital importance, therefore stating a need for a model to evaluate what affords the inhabitant's self-reliance and how this model could be used as support for the 'expert' to evaluate the inhabitant's capabilities towards their built environment. This article uses the rural locality as a case study with the intention for subsequent global (urban and rural) application.

Keywords: affordances, capability approach, collective intelligence, community of practice, rural selfreliance, situated knowledge, sustainable development.
\end{abstract}

\section{INTRODUCTION}

With a global population reaching 9.6 billion by 2050, UN [1] there is a rising demand for affordable housing. Paul Oliver does not think any government or corporation will be able to build the housing required, Cromley [2]. It will be up to local communities and inhabitants to develop their own dwellings. Existing informal rural (vernacular) architecture offer a flexible model based on locally available (renewable) materials and building methods. The available global vernacular models often evolved over centuries, passed down to every new generation. Due to the nature and character of the vernacular archetype, extensive maintenance is often essential, Fig. 1. However inconvenient, the continuous process of maintenance allows the community to constantly practice and enhance their built environment, Smits [3] and makes them highly resilient towards change, Nel and Binns [4]. Moreover, due to the choice of materials and construction properties the vernacular archetype has the ability to completely dissolve back into nature when its lifespan ceases. The circular sustainable model is still widely used among many rural African communities, which are simply striving to survive, Nel and Binns [4]. Over last decades rural communities

${ }^{1} \mathrm{PhD}$ promotor: Prof. dr. ir. T. Avermaete 
have been trying to improve the living quality of the vernacular model, but the change introduced industrialized materials and 'foreign' construction methodologies. In practice, this means, despite that durability and maintenance have improved, the process created significant external dependency (material, construction and labour). The modernization is unsustainable, non-circular and affecting both identity and culture, Rapoport [5]. What is equally important, it diminishes the community's self-reliance towards their built environment.

Whatever the reasons, communities do struggle to improve the quality of the existing model using only local, non-industrialised materials and familiar construction methods without external help. In an effort to augment the existing model, they use materials and techniques that lay outside the collective intelligence (CI) of the inhabitants. If these communities are to continue the self-reliant model, they need a way to upgrade the model (extend durability, lower maintenance) without damaging its qualities. This article does not elaborate on the various development models: sustainable, top-down or bottom-up. Development is perceived as a general societal aim on the realization of what Robert Chambers [6] calls 'good change'. Sustainable development is chosen as a general model for a balanced growth. Lélé [7] proposes a model with a strong emphasis on the ecological conditions necessary to support human well-being now and in the future, Fig. 2. This model will help the 'expert' to grasp what the inhabitant's capabilities in relation to their self-reliant built environment are; hopefully, sustaining the inhabitant's self-reliance towards their built environment.

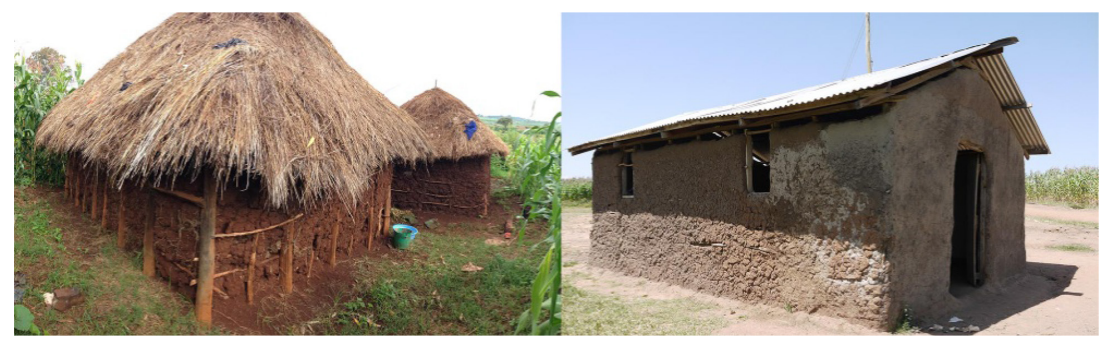

Figure 1: Rural vernacular, Mt. Elgon, Kenya, 2015 (made by author).

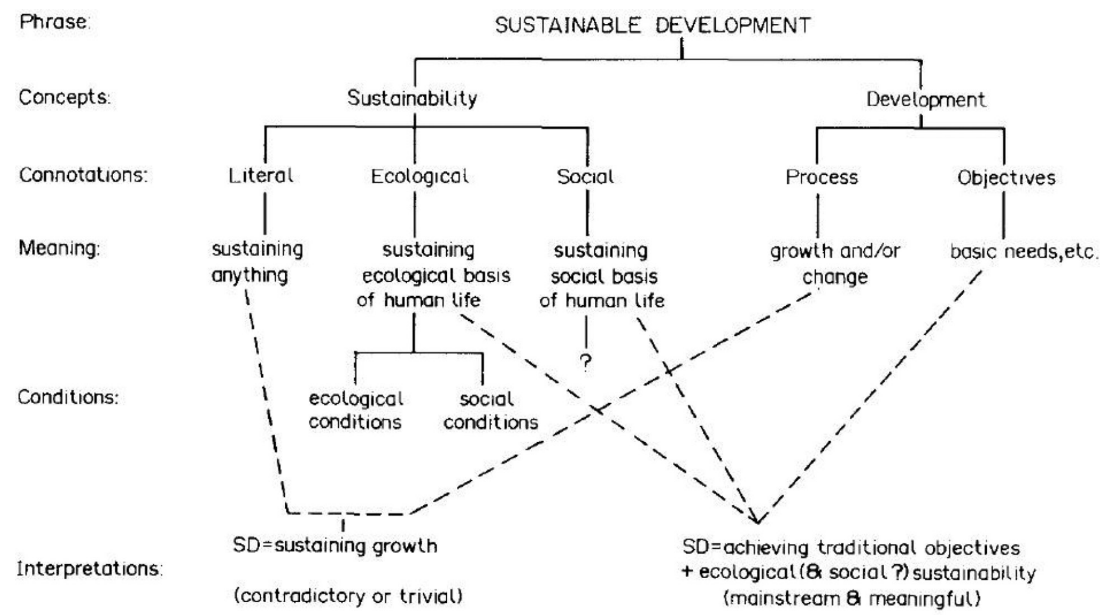

Figure 2: The semantics of sustainable development, Lélé [7]. 
Although total rural independence is an admirable goal, there will always be a relation to a form or degree of external support (material, construction method, labour, etc.). However, it could be of vital importance to improve the current (vernacular) model and should be the task for architects and engineers, Oliver [8]. With their expert knowledge on construction, materials and their ability to develop new ways, they could come up with techniques and methods, which are within the abilities and skills of inhabitant and without reaching for easy unsustainable solutions (e.g. iron sheet roofs). Achieving housing self-reliance would enhance the socio-economical situation of the inhabitants. It would also lessen the dependency from the western aid, making this effort a worthy goal. How the expert intervenes in this process is crucial to the self-reliance of the inhabitants, Prinet [9]. In order to properly improve the inhabitants built environment, the external support should evaluate current inhabitant's selfreliance towards their built environment. To help with doing so, the article firstly reviews what affords the community's self-reliance towards their built environment. Secondly how these affordances can be projected on their capabilities and thirdly, it articulates the model based on the capability approach (CA) to evaluate what affords the inhabitant's self-reliance.

\section{SELF-RELIANCE}

As introduced above, the rural vernacular tradition shows great sustainable and circular examples. They shed a completely different light on how environmental issues could be dealt with. Rural communities are able to construct and maintain their built environment with local renewable materials, circular processes and local knowledge, Idoma and Muhammad [10]. The community is almost fully able to provide necessary materials, technique and labour without external capital or help (outside one's community). For this reason self-reliance in this article is described as: the ability to independently provide a qualitative built environment on one's own power, knowledge, materials and construction methodologies, UNHCR [1]. Nonetheless, this self-reliant model is based on local, renewable but not durable materials, which decrease housing quality and increase the measure of maintenance, Ashby [11]. The change in lifestyle and general development demands alterations of the existing model. Without the evaluation of the communities capabilities, the chosen solutions might weaken the communities self-reliance, $\mathrm{Li}$ and $\mathrm{Ng}$ [12]. Li and $\mathrm{Ng}$ propose a Rural Built Environmental Sustainability Assessment System (RBESAS) to indicate the sustainability (balance) of the development, which is evaluated along two axes: Self-reliance Capability and Development

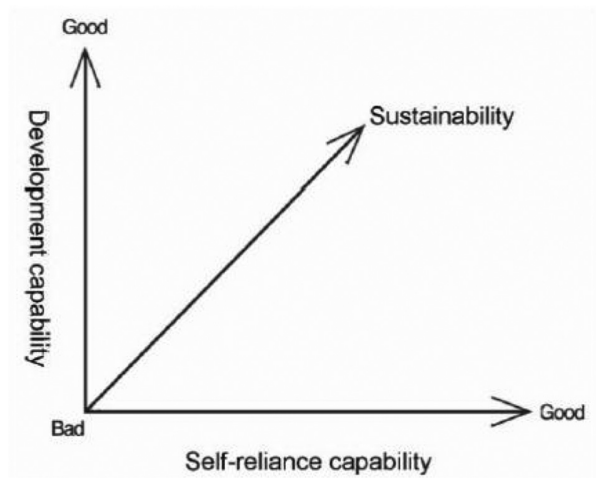

Figure 3: Built environment sustainability of poor rural areas, Li and NG [12]. 
Capability, Fig. 3. This model provides with an aim for sustainability that applies to both developing and developed world.

\subsection{From independence to dependence}

However, it proves troublesome to advance the existing informal sustainable model by inhabitants themselves. They often use materials and techniques (bricks, cement, steel, etc.) that are outside the community's knowledge sphere (capabilities). As a result, dependency on non-local materials, labour and knowledge often occurs. A tendency that can be traced back to the development strategies that often deliberately used dependency for external partners to benefit, Grudens-Schuck et al. [13]. If the communities are to remain self-reliant, a balance between their own and external capabilities ought to be found, Idoma and Muhammad [10]. Contemporary examples reveal that the 'expert' intervention by the professional is often problematic due to its technological character. Moreover to improve (enhance the quality of building within the inhabitant's reach of material, tools and methods) inhabitants' built environment, their self-reliance should be evaluated. The community's construction knowledge plays the most vital role for sustaining self-reliance towards their built environment. The importance of the local self-reliance (community-based, local resources, etc.) has been recently described in a new development theory called: African renaissance, Matunhu [14]. Fonchingong and Fonjong [15] explain that independence is important. However, there will be a necessity of external technical and financial support, as inhabitants themselves proved not to be able to formulate a sufficient way of upgrading their built environment, therefore concluding there is a role for the external support and knowledge.

\subsection{Collective intelligence, embedded knowledge and situated learning}

In the traditional built environment, the community acted as a collective to provide each other with habitation. Inhabitants (on the family scale) individually evaluated their situation within the built environment. The built environment provides with the most long lasting human artifacts as a part of our collective cultural memory, Cole [16]. Families were able to live self-reliantly but interdependent on other families (community). This group of families constructed and developed the dwelling archetype together. The archetype is a shared cultural perception, which is perceived as an articulation of a community's common goal. In other words, it means there is a 'collective intelligence' of the community towards their built environment. Leimeister [17] defines collective intelligence as a group of individuals who are not required to have the same point of view, but can have different perspectives and approaches. Their shared intelligence refers to their ability to learn, understand, and adapt to an environment. It enables the collective to deal with changing and difficult situations.

The collective intelligence of rural vernacular architecture often is misunderstood due to the lack of formalized knowledge. The absence of this 'explicit' knowledge, Allee [18] \& Frost [19], can be explained to the high level of intuitive and experience based knowledge. This 'tacit' knowledge, Polanyi [20], is deeply rooted in action, commitment and involvement, Nonaka [21]. Furthermore because of the community involvement, this 'embedded' knowledge, Collins [22], is articulated in all processes and products, concerning their built environment. It is not a model or a framework but a way of learning that occurs in the every day. A form of learning what Cobb and Bowers [23] calls situated learning: 


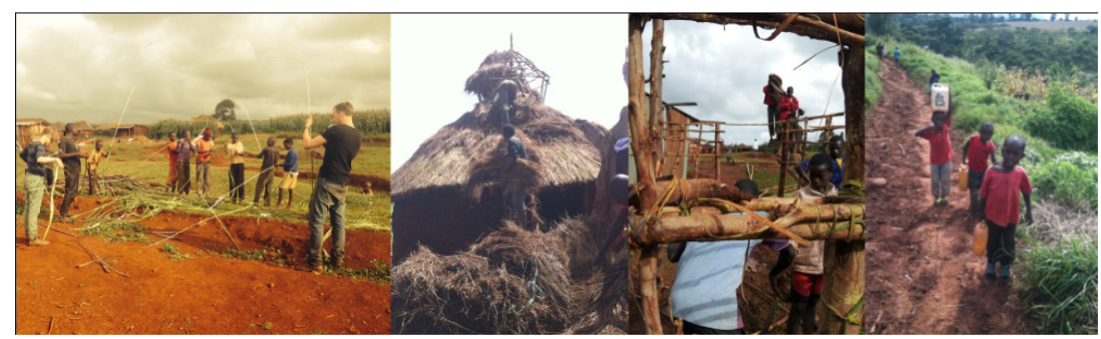

Figure 4: Various Communities of practice (CoP), Mt. Elgon, Kenya, 2011 (made by author).

'The theory of situated learning claims that knowledge is not a thing or set of descriptions or collection of facts and rules. [...] Human knowledge should be viewed as a capacity to coordinate and sequence behaviour, to adapt dynamically to changing circumstances.'

\subsection{Community of practice $(\mathrm{CoP})$}

The model of vernacular construction processes reveals itself as an example of the situated learning, Smith [24] \& Wenger [25], which is transferred by every generation of children, based on legitimate peripheral participation, Wenger [25]. It consists of various elements, such as: water fetching, mud mixing, wall filling and rope making, Fig. 4. Every task is performed by a mixed (age) group of participants and varied levels can be clearly distinguished (from novice to expert). This group is what Lave and Wenger call communities of practice (CoP). The participation in a CoP according to Wenger [26] is not only a shared activity but it encompasses a shared interest, which can involve people in any type of activity. These activities do not only concern construction but range to aspects of community (like: washing, bathing and cleaning). There is a major overlap in daily and constructing activities. However, they can be reduced to three basic elements as Wenger [25] proposes:

1. What it is about?

2. How does it function?

3. What capability it has produced?

\section{CAPABILITIES}

Capability generally means the quality of being capable; capacity; ability. Within the context of this article, capability is analysed to what extent one is capable or able to effectively formulate their built environment. Developing on one's own abilities will be essential for the self-reliance of sub-Sahara, Willer [27]. The capability approach (CA) is based on the same definition. Which, for this purpose, forms the departure point to understand what is realized (functionings) and what is actually possible (capabilities) by inhabitants. Capabilities are described as a person's ability to achieve a given functioning: doing or being, Sen [28].

\subsection{The capability approach}

The Capability Approach (CA) introduced by Sen formulates an alternative economic framework to look at poverty, inequality and human development in general, (qtd. Clark [29]). Sen 
[28] distinguishes basic capabilities. The basic capability is the ability to satisfy certain elementary functionings up to a certain level. For the purpose of this investigation of habitation, it is of vital importance for survival or to escape poverty, Robeyns [30]. Sen, describes this phenomenon as follows, (qtd. Clark [29]):

$$
\begin{aligned}
& \text { Commodity } \rightarrow \quad \underset{\text { (to function) }}{\text { Capability }} \rightarrow \quad \text { Function(ing) } \rightarrow \quad \text { Utility } \\
& \text { House } \rightarrow \quad \begin{array}{c}
\text { Housing } \\
\text { self-reliance }
\end{array} \rightarrow \quad \text { Escaping poverty } \rightarrow \quad \begin{array}{c}
\text { Being self-reliant/ } \\
\text { safe/happy }
\end{array}
\end{aligned}
$$

The capability approach is a normative economical framework that provides a theory on how (individual or group) well-being could be assessed. However, there are only few research examples that use the CA for the evaluation of a group's decision-making or evaluation process, Robeyns [30]. Li's and Ng's, investigation [12] seems one of the few examples that used the CA in the evaluation of the built environment. They formulated a list of indicators based on a set of capabilities, Fig. 5. Here a distinction between self-reliance and development capabilities is being made:

- Self-reliance capability: To meet basic human needs without over-reliance in outside resources under existing bio-capacity, and at the same time, does not reduce bio-capacity.

- Development capability: To increase the bio-capacity, and to meet human psychological needs for better development.

Li \& Ng used the indicators to analyse to what level they could successfully evaluate the sustainability of a rural community towards their built environment. However, uncertainty remains if the indicators cover all aspects of the capabilities. Moreover, it does not explain what the various indicators afford in relation to a self-reliant and sustainable build environment. This article will focus on deepening Regional materials (Fig. 5) by looking at one specific scenario: housing component (door) made out of two different regional materials (Mahogany hardwood $\&$ steel; see Table 1). For example: To understand how Regional materials (6.1, Fig. 5) enable Housing self-reliance (6, Fig. 5), firstly, there is a need to zoom in on the housing component. Secondly, what the possible available regional materials are. Thirdly, evaluate how they result in possible positive and negative affordance in relation to the user capabilities and self-reliance.

\subsection{Affordances of self-reliance}

To be able to describe the factors that influence the self-reliance capability indicators we can't solely look at how they interrelate and function. For example:

Factor A (door) + factor B (regional material) doesn't have to result in a sustainable regional material (6.1, Fig. 5)

The regional material could for instance be a local hardwood. Because it grows over decades, it could very well be unsustainable to use as a construction material. Moreover, this hardwood might be regional but not owned by the inhabitant. For this reason, the inhabitant would need financial capacity, which would (when used) influence other capacities (eating, drinking, learning). To look beyond the scope of functionings, Gibson proposes an affordances model (qtd. Maier and Fadel [31]). Here, the influence between the various factors is seen within their environment. An artifact is no longer perceived to result in a certain specific 


\begin{tabular}{|c|c|c|c|}
\hline & & $\begin{array}{l}\text { 1. Land \& resources } \\
\text { conservation }\end{array}$ & $\begin{array}{l}\text { 1.1 Sensitive areas conservation } \\
\text { 1.2 Agricultural land conservation } \\
\text { 1.3 Soil and water conservation }\end{array}$ \\
\hline & & 2. Waste management & $\begin{array}{l}\text { 2.1 Construction \& demolition waste management } \\
2.2 \text { Operation waste management }\end{array}$ \\
\hline & & 3. Pollution control & $\begin{array}{l}\text { 3.1 Pollution-free construction \& demolition } \\
\text { 3.2 Pollution-free agriculture }\end{array}$ \\
\hline & & 4. Food self-reliance & $\begin{array}{l}\text { 4.1 Local food production } \\
4.2 \text { Diversified farming }\end{array}$ \\
\hline & & 5. Water self-reliance & $\begin{array}{l}\text { 5.1 Water quality } \\
5.2 \text { Water efficient irrigation } \\
5.3 \text { Water efficient buildings \& appliance } \\
\text { 5.4 Water reuse }\end{array}$ \\
\hline & $\begin{array}{l}\text { Selt-reliance } \\
\text { capability }\end{array}$ & & 6.1 Regional materials \\
\hline & & 6. Housing self-reliance & $\begin{array}{l}\text { 6.2 Efficient use of materials } \\
6.3 \text { Indoor environmental quality } \\
6.4 \text { Housing affordability }\end{array}$ \\
\hline$\sum_{\substack{2 \\
s}}^{2}$ & & 7. Safety and security & $\begin{array}{l}\text { 7.1 Settlements location } \\
7.2 \text { Safety and security design }\end{array}$ \\
\hline$\underline{\simeq}$ & & 8. Health \& well-being & $\begin{array}{l}\text { 8.1 Living environmental sanitation } \\
\text { 8.2 Community basic services } \\
\text { 8.3 Community recreation facilities and open spaces }\end{array}$ \\
\hline & & 9. Energy self-reliance & $\begin{array}{l}\text { 9.1 Embodied energy of materials } \\
\text { 9.2 Energy efficient buildings \& appliance } \\
\text { 9.3 Local \& renewable energy }\end{array}$ \\
\hline & & 10. Economic self-reliance & $\begin{array}{l}\text { 10.1 Local economy improvement } \\
10.2 \text { Activation \& empower }\end{array}$ \\
\hline & & 11. Sustainable landscaping & 11.1 Biocapacity improvement \\
\hline & & 12. Sustainable agriculture & $\begin{array}{l}\text { 12.1 Circular agriculture } \\
12.2 \text { Biological controls }\end{array}$ \\
\hline & $\begin{array}{l}\text { Development } \\
\text { capability }\end{array}$ & 13. Culture \& context & $\begin{array}{l}\text { 13.1 Protection of historical \& cultural heritage } \\
\text { 13.2 Keep local characteristics } \\
\text { 13.3 Coordination with natural environment }\end{array}$ \\
\hline & & $\begin{array}{l}\text { 14. Inclusiveness \& } \\
\text { participation }\end{array}$ & $\begin{array}{l}\text { 14.1 Barrier-free facilities } \\
\text { 14.2 Public engagement }\end{array}$ \\
\hline & & 15. Education \& information & $\begin{array}{l}\text { 15.1 Education space and facilities } \\
\text { 15.2 Information facilities }\end{array}$ \\
\hline
\end{tabular}

Figure 5: Framework of RBESAS indicators, Li and NG [12].

function. It has the ability to afford many things (outside the scope of base function). Since not all affordances have positive effects, the theory makes a distinction between positive and negative affordances.

Maier and Fadel [32] use the affordances to formulate a framework in the evaluation of engineering and design processes. Uzzell and Clark [33] give a good example on the evaluation of affordances within the built environment. The artifact affords desired and undesired purpose(s). The artifact in the proposed new framework can either be a commodity, resource or skill (Maier and Fadel [34]). It can have either positive or negative affordances to a multitude of capabilities and, by being so, not only evaluating cause and effect, but a multitude of effects. Affordances can be divided into two broad categories, (Maier and Fadel [32, 35]): artifact-user affordances (AUA) and artifact-artifact affordances (AAA).

The proposed indicator, ( $\mathrm{Li}$ and $\mathrm{Ng}$ [12]); Regional material (6.1, Fig. 5) can be interpreted as one half of the total group of materials (regional/non-regional materials). In the provided example, two materials mahogany hardwood and steel (regional/non-regional materials) are evaluated and applied in the housing part: a door. The main structure of generic affordance template of Maier and Fadel [32] (white boxes) is used, Fig. 6. 


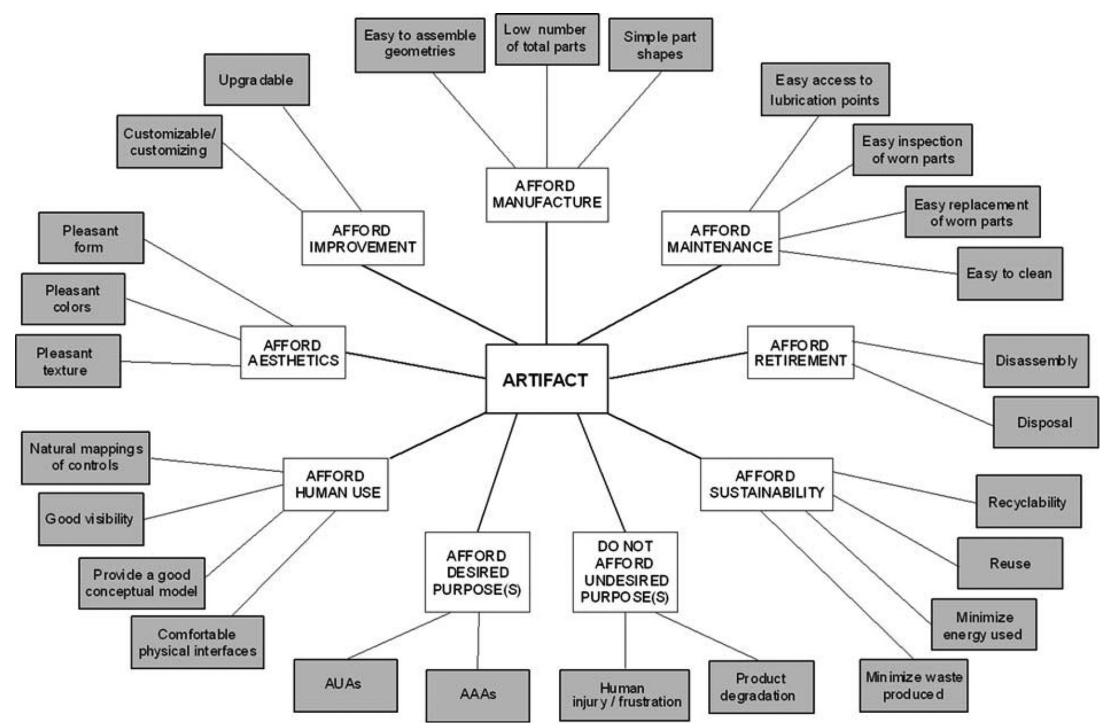

Figure 6: Generic affordance structure template, Maier and Fadel [32].

\section{A MODEL TO EVALUATE AFFORDANCES THAT ENABLE COMMUNITY}

CAPABILITIES TOWARDS THEIR SELF-RELIANT BUILT ENVIRONMENT

This article argues that although Gibson's CA gives a model to understand individual wellbeing, it does not evaluate the interrelations between resources (commodities and skills) and capabilities (qtd. Maier and Fadel [31]). Moreover, it narrows commodities as the functional part of a capability, as an effect the characteristics (positive and negative affordances) are not sufficiently evaluated. To evaluate and incorporate these aspects, this article outlines the following addition to the model:

\begin{tabular}{|c|c|c|c|c|c|c|c|c|}
\hline Artifact & $\rightarrow$ & $\begin{array}{l}\text { Positive } \\
\text { Affordance(s)/ } \\
\text { Negative } \\
\text { affordance(s) }\end{array}$ & $\rightarrow$ & $\begin{array}{l}\text { Capability } \\
\text { (to } \\
\text { function) }\end{array}$ & $\rightarrow$ & Function(ing) & $\rightarrow$ & Utility \\
\hline $\begin{array}{l}\text { (All materials } \\
\text { used to build } \\
\text { a house) e.g.: } \\
\text { Mahogany } \\
\text { hardwood }\end{array}$ & $\rightarrow$ & $\begin{array}{l}\text { Positive } \\
\text { affordances/ } \\
\text { Negative } \\
\text { affordances }\end{array}$ & $\rightarrow$ & $\begin{array}{l}\text { Housing } \\
\text { self- } \\
\text { reliance }\end{array}$ & $\rightarrow$ & $\begin{array}{l}\text { Escaping } \\
\text { poverty }\end{array}$ & $\rightarrow$ & $\begin{array}{l}\text { Being } \\
\text { self- } \\
\text { reliant/ } \\
\text { safe/ } \\
\text { happy }\end{array}$ \\
\hline
\end{tabular}

To solve the complexity of relations Maier et al. [36] proposes several matrix-based methods: Design Structure Matrices (DSMs) and House of Quality (HoQ). These have been developed to evaluate the information and relationships in engineering systems, but could be of vital importance to explain complex designer user relationships. However, their analysis also focuses mainly on requirements and functions. Maier and Fadel [32] propose an Affordance Structure Matrix (ASM), which is similar to DSM and HoQ, but is specific to affordances. Here the different affordances are weighed against the different components of a certain artifact. 
Looking at the indicators (Fig. 5) of $\mathrm{Li}$ and $\mathrm{Ng}$ [12] to evaluate self-reliant housing (regional materials, efficient use of materials, indoor environmental quality, housing affordability), it could be argued if they can sufficiently cover all capabilities (in relation to self-reliant housing). In an effort to formulate a clear and complete scope of all capabilities relating to self-reliant housing, the following capabilities are proposed:

- Maintainability

- Affordability

- Liveability

- Improvability

- Aesthetics

- Sustainability

- Suitability

- Flexibility

- Usability

- Comfortability

This list of capabilities is merely an attempt to cover the different themes related to selfreliant housing. Any such endeavour without the direct involvement and evaluation of a given situation (inhabitant/community) seems futile. However, it is necessary in order to properly analyse all dimensions of such circumstances as input to the model described in this article. The described model in this article is not meant as a critique on the CA, but more an applied articulation to the field of the built environment. It tries to help inhabitants to sustain a selfreliant attitude towards their built environment. In Table 1, the various affordances are described and weighed in relation to regional materials on the example of a door as one of the house components (the model can be used for all elements of the dwelling, e.g. window frame, foundation, roof).

In the example above the two materials (mahogany hardwood and steel) are evaluated as a part of a door example in the following elements:

1. How many positive affordances does each option have.

2. How many negative affordances does each option have.

3. Total number of helpful relationships (positive affordance an option has plus the number of negative affordances it does not have).

4. Total number of harmful relationships (positive affordances an option does not have plus the number of negative affordances it does have).

5. Percentage helpful.

6. Percentage harmful.

7. Percentage difference (percentage helpful minus percentage harmful).

As shown in Table 1, using the list of capabilities as a departure point, various affordances (positive and negative) for both AUA and artifact-artifact affordances can be formulated. Moreover, the number of helpful and harmful relationships can be evaluated and an overall helpful or harmful percentage can be calculated. In this case, it results in a largely positive evaluation of the mahogany hardwood door and a rather negative evaluation of the steel. Both results weighted on the affordances based on the possible capabilities of the inhab- 
Table 1: List of weighted positive and negative affordances on the example of a door (one of the house components) "+" equals the presence of the positive affordance; "-" equals the presence of the negative affordance.

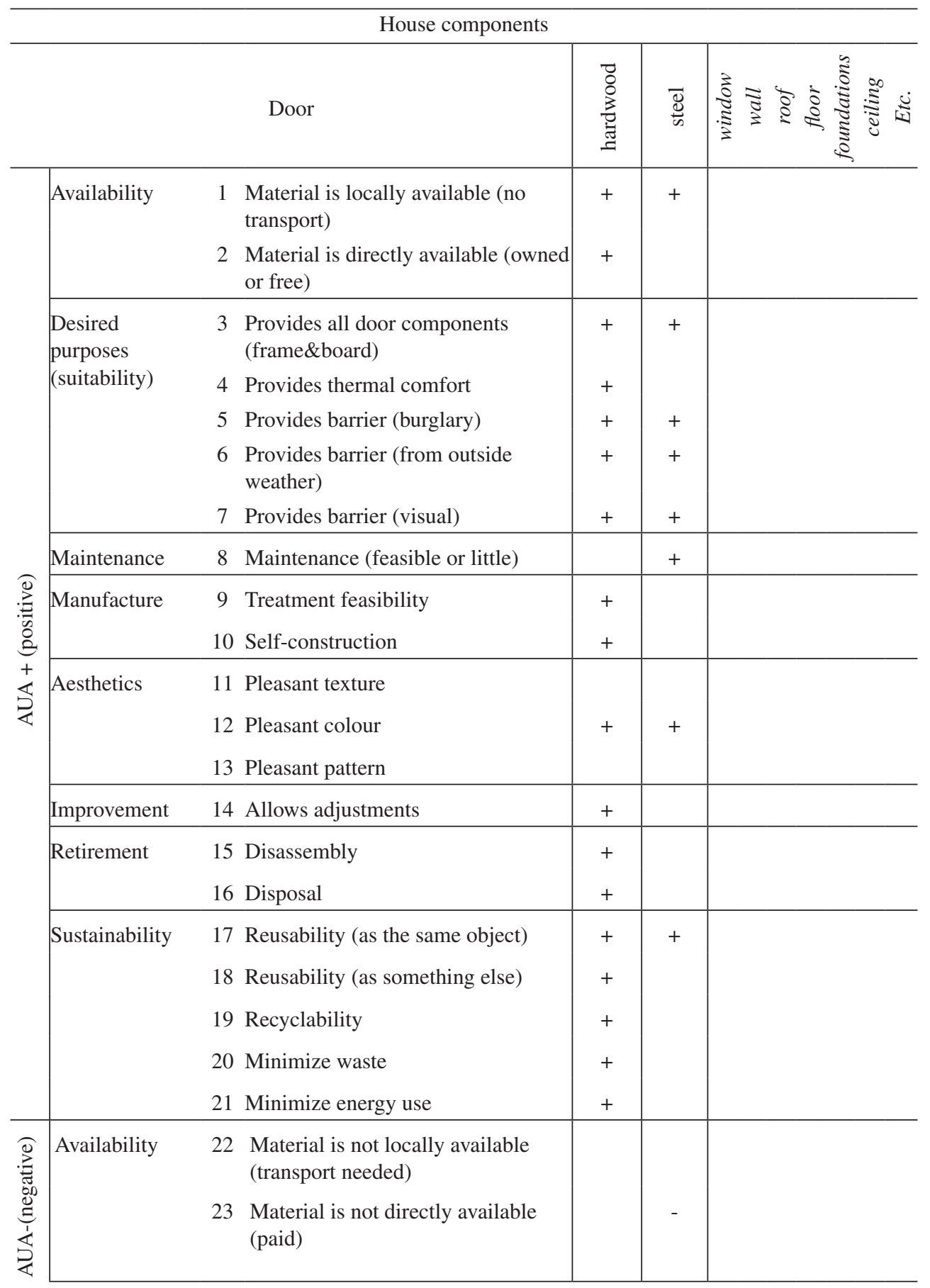




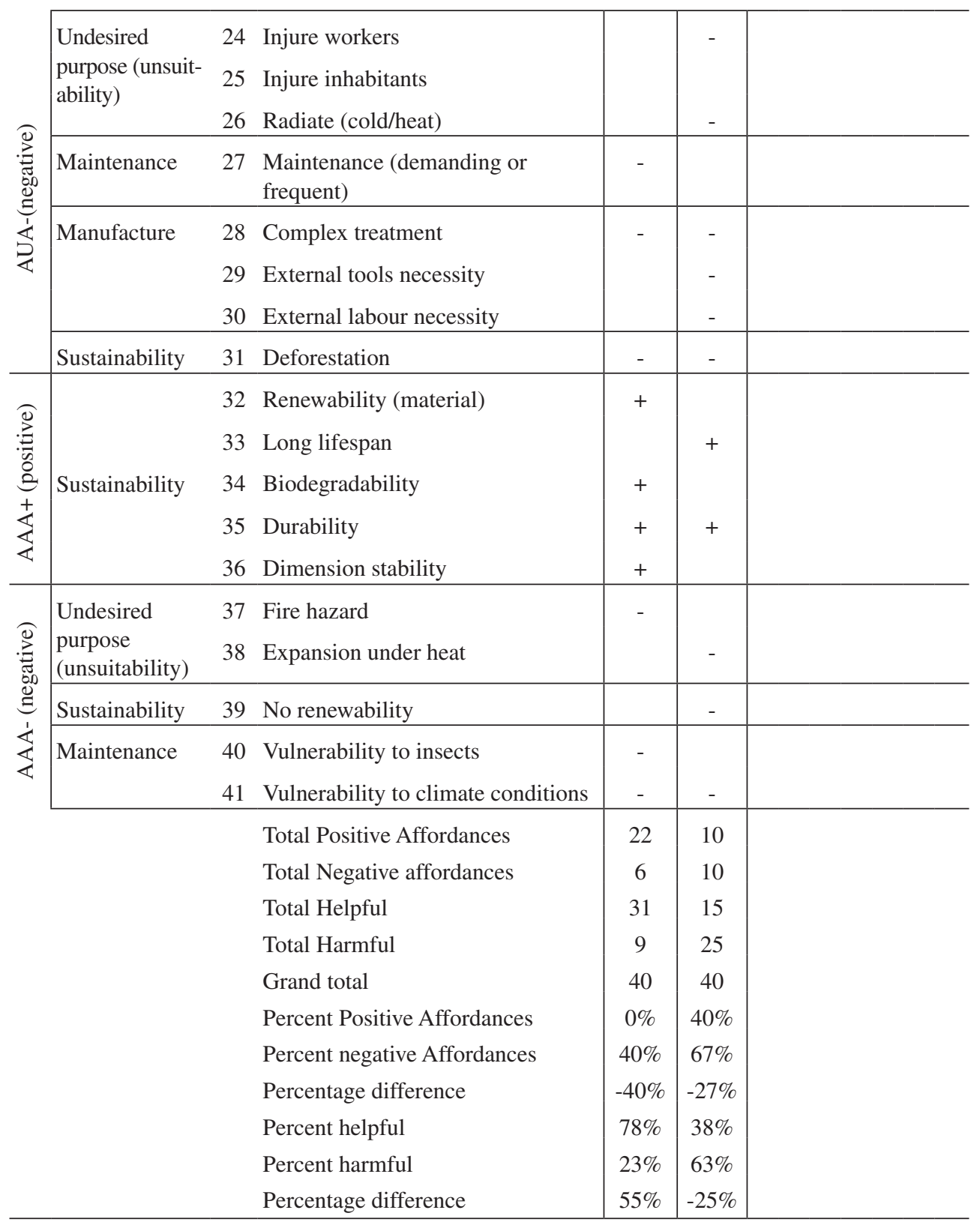

itant (assumed) are aiming to advise the most self-reliant and sustainable option for the inhabitant.

Note: in this example equal weighting is assumed for each affordance. A comparable ASM could be described not only for one part (door) but also for a group of parts and even a whole house (self-reliant housing). In this matrix, the various affordances necessary for self-reliant housing can be evaluated in relation to the house component per material. 


\section{CONCLUSION}

This article has outlined different approaches to understand how user capabilities can be related to the build environment based on affordances. As a result it identified a (ASM) model where the affordances can be weighted and evaluated according to the housing component per material. The list of affordances articulated and prioritised in this article was formulated without user involvement. This list gives a theoretical list of affordances to be evaluated together with the user for completeness. It should be understood that the developed model is not intended to cover all aspects within the built environment. It attempts to improve insight in the major aspects considering the suitability of undertaken decisions. In the subsequent article the model is operationalized as support tool. A board game in combination with a survey will generate the user's capabilities as input to the model. The model will uncover the possible affordances and evaluate the suitability per dwelling component in an effort to sustain or increase the level of self-reliance of users towards their built environment.

\section{REFERENCES}

[1] UNHCR, Handbook of Self-Reliance, Operational Publications, 2006.

[2] Cromley, E., Cultural embeddedness in vernacular architecture. Building Research \& Information, 36(3), pp. 301-304, 2008. http://dx.doi.org/10.1080/09613210801902995

[3] Smits, M., An architect's investigation into the self-reliance of a Sub-Saharan African community, 2014, available at: https://www.researchgate.net/publication/286457181

[4] Nel, E. \& Binns, T., Rural self-reliance strategies in South Africa: community initiatives and external support in the former black homelands. Journal of Rural Studies, 16, pp. 367-377, 2000. http://dx.doi.org/10.1016/S0743-0167(00)00003-6

[5] Rapoport, A., Some further thoughts on culture and environment. International Journal of Architectural Research, 2(1), pp. 16-39, 2008.

[6] Chambers, R., Poverty and livelihoods: Whose reality counts? Environment and Urbanization, 7(1), pp. 173-204, 1995. http://dx.doi.org/10.1177/095624789500700106

[7] Lélé, S.M., Sustainable development: A critical review. World Development, 19(6), pp. 607-621, 1991. http://dx.doi.org/10.1016/0305-750X(91)90197-P

[8] Oliver, P., Built to Meet Needs: Cultural Issues in Vernacular Architecture, Architectural Press: Oxford, 2006.

[9] Prinet, E.J., Rural self-reliance strategies in South Africa: community initiatives and external support in the former black homelands (Master's thesis, The University of British Columbia, Vancouver, Canada, 2000), available at: https://open.library.ubc.ca/cIRcle/ collections/ubctheses/831/items/1.0089327

[10] Idoma, K. \& Muhammad, I., Self-reliance: key to sustainable rural development in Nigeria. ARPN Journal of Science and Technology, 3(6), pp. 585-592, 2013.

[11] Ashby, M.F., Materials and the Environment: Eco-Informed Material Choice, Butterworth-Heinemann: Waltham, USA, 2012.

[12] Li, W. \& Ng, E., Built environment sustainability assessment of poor rural areas of southwest China. Conference Proceeding PLEA 2014, eds R. Rawal, S. Manu \& S. Khadpekar, CEPT University Press: Ahmedabad, India, 2014. 
[13] Grudens-Schuck, N., Allen, W., Hargrove, T.M. \& Kilivington, M., Renovating dependency and self-reliance for participatory sustainable development. Agriculture and Human Values, 20, pp. 53-64, 2003. http://dx.doi.org/10.1023/A:1022412623083

[14] Matunhu, J., A critique of modernization and dependency theories in Africa: Critical assessment. African Journal of History and Culture, 3(5), pp. 65-72, 2011.

[15] Fonchingong, C.C. \& Fonjong, L.N., The concept of self-reliance in community development initiatives in the cameroon grassfields. Nordic Journal of African Studies, 12(2), pp. 196-219, 2003.

[16] Cole, R.J., Review: time and responsibility: extending the concept of the present. Building Research \& Information, 28(4), pp. 291-295, 2000.

http://dx.doi.org/10.1080/09613210050073742

[17] Leimeister, J.M., Collective intelligence. Business \& Information Systems Engineering, 2(4), pp. 245-248, 2010.

http://dx.doi.org/10.1007/s12599-010-0114-8

[18] Allee, V., Knowledge networks and communities of practice. OD Practitioner, 32(4), pp. 1-15, 2000.

[19] Frost, A., The different types of knowledge, available at: http://www.knowledge-management-tools.net/different-types-of-knowledge.html\#ixzz3tg0FGVP4

[20] Polanyi, M., Personal Knowledge: Towards a Post-Critical Philosophy, University of Chicago Press: Chicago, USA, 1962.

[21] Nonaka, I., A dynamic theory of organizational knowledge creation. Organization Science, 5(1), pp. 14-37, 1994.

http://dx.doi.org/10.1287/orsc.5.1.14

[22] Collins, H.M., The structure of knowledge. Social research. An International Quarterly, 60(1), pp. 95-116, 1993.

[23] Cobb, P. \& Bowers, J., Cognitive and situated learning perspectives in theory and practice. Educational Researcher, 28(2), pp. 4-15, 1999.

http://dx.doi.org/10.3102/0013189X028002004

[24] Smith, M.K., Jean Lave, Etienne Wenger and communities of practice. The encyclopedia of informal education, 2003, available at: www.infed.org/biblio/communities_of_ practice.htm

[25] Wenger, E., Communities of practice and social learning systems: the career of a concept, available at: http://wenger-trayner.com/wp-content/uploads/2012/01/0910-27-CoPs-and-systems-v2.01.pdf

[26] Wenger, E., Communities of Practice; Learning, Meaning and Identity, Cambridge Press: Cambridge, 1999.

[27] Willer, H., Review: Foreign Aid, Self-Reliance, and Economic Development in West Africa, ed. R.O. Olaniyan, Praeger Publisher: Westport, 1996.

[28] Sen, A.K., Capability and well-being. The Quality of Life, eds M.C. Nussbaum \& A.K. Sen, Clarendon Press: Oxford, pp. 30-53, 1993.

[29] Clark, D.A., The capability approach: its development, critiques and recent advances. Economics Series Working Papers GPRG-WPS-032, University of Oxford, Department of Economics: Oxford, 2005.

[30] Robeyns, I., The capability approach. The Stanford Encyclopedia of Philosophy ed. E.N. Zalta, 2011, available at: http://plato.stanford.edu/archives/sum2011/entries/capability-approach/ 
[31] Maier, J.R. \& Fadel, G.M., Comparing function and affordance as bases for design. Proceedings of DECT'02, Montreal, Canada, 2002.

[32] Maier, J.R. \& Fadel, G.M., Affordance based design methods for innovative design, redesign and reverse engineering. Research in Engineering Design, 20(4), pp. 225-239, 2009.

http://dx.doi.org/10.1007/s00163-009-0064-7

[33] Uzzell, D. \& Clark, C., The affordances of the home, neighborhood, school, and town centre for adolescents. Journal of Environmental Psychology, 22(1-2), pp. 95-108, 2002.

http://dx.doi.org/10.1006/jevp.2001.0242

[34] Maier, J.R. \& Fadel, G.M., An affordance-based approach to architectural theory, design, and practice. Design Studies, 30(4), pp. 393-414, 2009. http://dx.doi.org/10.1016/j.destud.2009.01.002

[35] Maier, J.R. \& Fadel, G.M., Affordance based design: a relational theory for design. Research in Engineering Design, 20(4), pp. 13-27, 2009. http://dx.doi.org/10.1007/s00163-008-0060-3

[36] Maier, J.R., Ezhilan, T. \& Fadel, G.M., The affordance structure matrix: a concept exploration and attention directing tool for affordance based design. Proceeding ASME Conference, pp. 277-287, 2007. http://dx.doi.org/10.1115/DETC2007-34526 